\title{
Bilingual Lexicography from a Pragmatic Viewpoint in English-Albanian and Albanian-English Dictionaries
}

Mirela Prifti

University of Tirana, Tirana, Albania

Doi:10.5901/jesr.2014.v4n4p508

Over the last decades the connections and the contacts settled between English and Albanian language have been increased significantly. The status of English as an international language but even as the first language Albanians are facing with in any moment and in any branch of the scientific, economic, cultural, political, military and social life raised my interest to consider this issue from a deep scientific viewpoint. During the process of learning English and the innumerable translations, the Albanians who are trying to learn or master this language, firstly are confronting with its lexical and semantic structure. The lexical structure of both these languages implies their lexical and idiomatic treasure.

At this point, it should be considered the fact that English is one of the languages with the highest level of standardization and its means of expressions are much wider and various compared to Albanian. We may refer to the explanatory dictionaries of both languages to notice this phenomenon. There are hundreds and thousands active English dictionaries which have been compiled in English speaking and non English speaking territories. An invaluable range of words and idiomatic units are mirrored in their interiors.

Nowadays the bond between English and Albanian, which have become very complex, is defined even by the linguistic politics that have been implied by the Albanian government in the graduate and post graduate educational system. English has become the second compulsory language in all educational chain; it is implemented in all university faculties and recently the IELTS and the TOEFL exams have become a must for all the students who want to receive a post graduate diploma or to attend a PhD.

This entire situation leads the Albanians to the English dictionary and grammar pattern as the two basic lines to learn a foreign language. Dictionaries pertain to different types and they have been compiled according to different lexicographical techniques. A successful Albanian lexicographer, prof. Jani Thomai, states that "firstly a dictionary is a mirror of words, idioms and their lexical meanings. But every single dictionary, furthermore every single explanatory national dictionary, is a phonetic mirror of the language as well (regarding the sounds, the spelling and the accent of the words); it is partially a grammatical mirror..., it is a much wider semantic mirror compared to the lexis; and finally it is a stylistic mirror connected with the preservation of the lexical norm in general ..."

Language lexicography implies the theory and the practice of the compilation of different types and kinds of dictionaries. They are organized thematically, according to the material they present, or according to the compiling lexicographical techniques.

According to the principles of dictionary compilation and the material they consist of, there are several kinds of dictionaries:

Based on the kind of information they include, there are two kinds of dictionaries:

Linguistic dictionaries that focus on the explanation of words and idioms meanings. They can be one-language, bilingual or multi-language dictionaries; explanatory, terminological, idiomatic, etymological dictionaries, etc.

Non linguistic dictionaries which generally implies the encyclopedia dictionaries which explains scientific concepts.

According to their width and volume, the dictionaries are classified into three categories:

Integral (thesaurus) dictionary, which includes the entire lexis of a language. Unfortunately, Albanian language does not possess any similar dictionaries. Its compilation has become a must and recently all the linguistic and lexicographical institutions have been working intensively to publish one.

Average dictionary, where there is included the essential part of a language lexis.

Small dictionaries, which include the basic and the most common words of a language.

According to the mode the words are arranged in a dictionary, they might be alphabetic and aversive. But they may also be arranged in nests, that is to say in families, from the root word to all the other ones which derive form it; for 
example, the nest of the word "employ" is: employ-employee-employer-employment and all the other corresponding expressions, idioms and phrasal verbs that are connected with it. (examples in the video projector)

Albanian language lexicography is the earliest and the richest branch in our linguistic development. We may also accept the fact that Albanian linguistic history commences with a lexicographical masterpiece, with a dictionary. Its history is divided in two periods:

The first one is marked by the publication of the first Albanian dictionary "Latin-Albanian dictionary" compiled by Frang Bardhi, in 1635. This dictionary came as a need to translate several religious works into Albanian. It is not a coincidence the fact that many linguists have evaluated the great value of this Dictionary, particularly as an important means to study the grammatical and the lexical structure of the Albanian language. This fact indicates that the value of this dictionary has been multidimensional and it has had an important role in the first stage of standardization of our language.

Actually, it was Arnold von Harf who organized the first glossary in Albanian during his pilgrimage through the "holy countries" in 1496. Because of his practical needs, he noted 26 words, 8 expressions and the numbers 1 to 10 , and 100 and 1000 accompanying them with the German translation. This glossary was published for the first time in 1860, in Köln.

In the first period, several types of dictionaries were compiled, mostly they were bilingual dictionaries, regional dictionaries, etymological dictionaries, etc.

The second period commences after the Second World War and continues until nowadays. During these years Albania has become an important center of lexicographical and dictionary compilation studies.

Over the last 100 years, it has been noticed a significant number of dictionary publications, which have been appreciated for their improved scientific level thus becoming a rapid answer to the direct requests connected with the diverse and deep developments Albanian language has been confronted with. The general lexicographical fund includes over 500 masterpieces, an invaluable inheritance which have kept improving century by century not only in quantity but in quality as well.

The main dictionaries are:

Albanian language dictionary (1954), with 25000 words, which is the first explanatory national dictionary.

Nowadays Albanian language dictionary (1980), with more than 42000 words and about 7000 idioms. It deals with the normative lexicographical codification in all language aspects; in spelling, in morphological cases, etc.

In 2006, "Albanian Language Dictionary" was published with 48000 words and 5000 idiomatic units.

A dictionary is a new lexicographical work, which preserves in the highest degree the main values of previous dictionaries aims to increase these values in words and meanings, in macrostructure, and even in the construction of every single lexicographical entry, in microstructure. In the dictionary, the lexicographers have involved a lot of words, expressions and meanings which are used in modern Albanian and are not found in the previous explanatory dictionaries.

B. Great achievements have been marked even in bilingual dictionaries, particularly, English-Albanian or Albanian - English lexicography, according to the circumstances and the practice requests. Among the most successful ones, we may refer to the publications of Pavli Qesku, such as: Albanian-English dictionary with 45500 words and English-Albanian dictionary with 126.000 new entries and 600.000 examples and idioms.

$\star * \star$

In English lexicography, there is another situation. Here, the achievements have been much more successful. Its embraces in its fund all the types of dictionaries, either printed or electronic ones.

The modern English lexis is not the creation of a single person, and it has not been developed within a single époque. It is the result of a development which has become alive over the centuries.

The term "English lexicography" is interpreted broadly to embrace dictionaries of Scots, of American English, and of the varieties of English spoken in Australia, in Canada, India, New Zealand, and South Africa. It is also taken to apply to dictionaries of the English based Creoles and Caribbean.

The elaborate, large-scale dictionaries of today evolved by stages from simple beginnings. In the seventh and eighth century, the practice arose of inserting in Latin manuscript explanations or "glosses", of difficult words in Latin or in Old English. Later, the glosses were gathered together in glossaries which were of three types: the ones arranged without an order, alphabetically arranged glossaries, and the ones arranged according to semantic fields (e.g. parts of the body, farm tools, etc.) which are "class glossaries".

From the middle of the sixteenth century onwards, a number of bilingual dictionaries appeared featuring English and a modern European language. These were explanatory dictionaries for English learners of the language in question, such as French, Italian and later on Spanish, German and Russian. By the end of the seventeenth century, with monolingual English dictionaries by that time well established, bilingual works which combined English and another modern foreign language profited from the general decline of Latin and played a major part in the promotion of various 
national tongues.

By the middle of the eighteenth century, monolingual dictionaries of English had so grown in scope and authority that several bilingual lexicographers, from various European countries, could contemplate using their word-lists as the basis of new dictionaries.

Generally speaking, and understandably, the linguistic needs of the time were often severely practical, so that bilingual dictionaries appearing in the nineteenth century, and featuring English, had increasingly to fulfil a demand for the standard language but also to satisfy a need for colloquial usage.

The decisive step in the development of modern dictionaries was taken in the eighteenth century, by one of the most prominent names in the English lexicography, Nathan Bailey. He is the author of the Universal Etymological Dictionary of English Language, published in 1721. He was the first who included the accent in the pronunciation of the words and the first to involve proverbs as well.

By the end of the eighteenth century, there was an urgent need to compile a standard dictionary of English language. In 1747, a syndicate was founded in London, composed of six writers, who accepted to collaborate with Samuel Johnson, to compile the first standard dictionary within a three-year span. The exemplary job made by Johnson, immediately raised the English lexicography in a higher level. The success of this dictionary was absolute, thus the next generations of lexicographers did not try to challenge it, but only to improve and to master it further. One pioneering feature of the Dictionary for which Johnson is now just applauded, is his treatment of phrasal verbs, which in Bailey's dictionaries are almost entirely ignored.

In the middle of the nineteenth century, Dr. Trench brought a new theory; he pretended that the rare words of the English language had never been collected and thousands words were not involved in the summary job made by Johnson and his colleagues. Consequently, he created the Philological Association which would "cure" the products of the predecessors. The publication of Oxford English Dictionary was the climax of this impulse. It was not only intended to include all the words used in the last 800 years, with their spelling, definitions and accompanying explanations, but also to represent a biography of every single word with all the corresponding changes which had occurred over their use.

I would also like to highlight the outstanding importance of Noah Webster's presence in the scene of the English lexicographical development. He compiled the first major American dictionary for use in the United States An American Dictionary of the English Language, published in 1828. Its publication is regarded as a landmark in American lexicography. According to Webster, the English language had developed a distinctive character in America and deserved its own dictionary. Thus, he published a dictionary of his own, with extraordinary values, where he included some prominent changes in spelling which later became part of the standard language in America.

Nowadays, in the English lexicography, data-bases have been created for dictionaries of different kinds, with approximately 230.000 .000 units, a treasure which is envied by all the other important international languages. There are rendered masterpieces, such as Webster's work, the big English Dictionary with 1.000 .000 lexical units, etc.

***

Generally, a dictionary is a linguistic work which contains a vast number of words rendered chronologically, accompanied with the respective explanations for their lexical meanings (in the explanatory dictionaries), or the corresponding words in another language (in bilingual or multilingual dictionaries), as well as the derivative terms, the necessary grammatical or stylistic explanations regarding the field they are used, quotations, examples, etc.

In the traditional Albanian dictionaries, the entry words are rendered alphabetically, without being followed by their derivative forms. In the explanatory Albanian dictionaries, as well as in the English ones, the idiomatic units are included within the lexicographical unit that has been settled up by the entry word. Thus in such dictionaries, we may not find only the full lexical structure of the word, but even the idiomatic units which are motivated structurally, but even semantically by this word. This arrangement composes a lexicographical nest. A nest implies a lexical unit group or a lexemic unit of a certain thematic field that are morphemically or semantically motivated. The units that participate in this nest have a direct or an indirect word-formation connection, with the entry word (supportive examples in the video projector).

The newest and the most complex Albanian dictionary, Albanian language dictionary (2006), is a practical dictionary, with the same volume as the Oxford dictionaries, but it is still called a small dictionary, even though it is composed of 48.000 words and 5.000 phrasal units. It is the first explanatory dictionary where nests have been used. So, it is arranged based on the lexicographical technique which has been successfully used in the international lexicography, and particularly in the English one.

This dictionary consists of at least 12 kinds of nests or lexemes groups included in one lexicographical unit. Some of these nests are only typical of Albanian language, based on its grammatical structure, but still correspondence between English and Albanian can be found.

Some of the most prominent nests are: 
The nests of the active verbs, the gerunds, the participle adjectives and their nominative forms if there is any, which have got essentially similar meaning structure.

The word-formation paradigmatic nests where the nouns and the adjectives which define the nationality of the peoples or of the historic inhabitants are unified in the same family, the feminine nouns follow the masculine ones (as gender is a key grammatical feature for nouns in Albanian).

The masculine and the feminine nouns have been included in the same nest, in cases when the feminine nouns have been directly motivated morphologically by the masculine ones and vice versa.

Another type of nest is created by the cardinal and ordinal numbers and all their derivatives.

The adverbs that derive from the corresponding adjectives are included in the same nest.

There are some seven other kinds of nests but they smaller in volume and furthermore, they are closely and only related with some lexical and grammatical features of Albanian language.

Regarding English language, it is one of the most explored and developed languages in the world. We should accept the fact that all its dictionaries consist of nests due to the effects of linguistic economy. So, within one lexicographical unit, it is not included only the entry word and the phrasal units that are connected with it, but even other lexicological units (words) which have derived from the root word.

One of the most popular explanatory English dictionaries in Albania is The Advanced Learner's Dictionary of Current English, compiled by Hornby. Even though, it became available in a period when the modern computerized techniques for the compilation of dictionaries missed, it is still practical nowadays. There are hundreds and thousands of nests included in this dictionary.

Over the last thirty years when the computerized techniques have been used extensively, the compilation of English dictionaries have become a typical industry. Nests are present in almost all the dictionaries, but they way they have been arranged is not unique. So, I would like to consider shortly one of the most prominent lexical and semantic feature that is the homonymy.

English is one of the languages that consists of a lot of homonyms, quite differently from the Albanian language which has got about 1050 words or 500 couples of homonyms. Generally, homonyms are divided into two big groups: in full lexical homonyms (when they pertain to the same lexical-grammatical category), and partial homonyms when two words are the same in one element of the paradigm, such as the homographs and homophones.

Albanian language is characterized only by the full homonyms, when two words pertain to the same part of speech and have got a full paradigm in conjugation and other typical grammar features (pg. 74).

In the Albanian lexicography, the words are ordered according to their signal values, or their grammar and lexical functions. So, a word is firstly explained in its function as a noun, a verb, an adjective, an adverb and later its other grammatical functions are rendered. But in English the situation is not the same. For example, the word well, in one of the best English dictionaries, is explained as an adverb, as an adjective, as an exclamation, and it is only in the end that it is given as a noun a noun.

However, different techniques of homonymy order have been inherited even in bilingual dictionaries where English is the first language and generally, the Albanian lexicographical order is not considered.

In a one-language or bilingual dictionary, the nests might be of different volumes, regarding their lexical and semantic material they include. This is connected with the values of a word in a language. Because the word as a linguistic unit has got semantic, emotional, stylistic, word-formation, paradigmatic and substitutive values (pg. 87).

Anyway, the nests in the bilingual dictionaries where English is the first language, depend even on the lexicographical customs of dictionary compilation in the second language, which in our case is Albanian.

$\star \star *$

There is much more to be mentioned regarding the contacts between English and Albanian language which cannot be summarized within a few minutes. However, the fact that English is influencing on our language not only structurally but in real terms of vocabulary of daily use, is becoming a common phenomenon. Albanians are trying to benefit from this process in order to recover the situation of poverty in the lexical system, always being attentive not to spoil the originality of Albanian language which has been preserved and evolved over the centuries. 